Research Article

\title{
Implementation of Computer-Based Vision Technology to Consider Visual Form of Ceramic Mural Art
}

\author{
Dazhuang Li $\mathbb{i}^{1}$ and Emad Saadi Alkathir $\mathbb{D}^{2}$ \\ ${ }^{1}$ Faculty of Humanities and Arts, Macau University of Science and Technology, Macau 999078, China \\ ${ }^{2}$ Department of Computer Engineering, Pardis Branch, Islamic Azad University, Tehran, Iran \\ Correspondence should be addressed to Dazhuang Li; lidazhuang311@163.com and Emad Saadi Alkathir; e.alkathir@gmail.com
}

Received 15 July 2021; Revised 9 August 2021; Accepted 12 August 2021; Published 30 August 2021

Academic Editor: Mohammad Yazdi

Copyright (c) 2021 Dazhuang Li and Emad Saadi Alkathir. This is an open access article distributed under the Creative Commons Attribution License, which permits unrestricted use, distribution, and reproduction in any medium, provided the original work is properly cited.

\begin{abstract}
As one of the cultural forms of human beings, ceramic murals transcend the dimension of time and space and transcend the single cognition of materialism in the sense of purely material materials. The emergence of computer vision technology has also provided conditions for developing ceramic murals in terms of concepts and technical forms. This article first studies the visual communication language research in ceramic mural art, at the same time comprehensively analyzes the design principles of ceramic mural art, and interprets the visual form of ceramic mural art from the perspective of actual projects in the thesis; then, it boldly analyzes the future of ceramic mural art Development trend. Finally, this article analyzes the composition in ceramic mural art, the graphics in ceramic mural art, the color in ceramic mural art, the scale in ceramic mural art, the lighting in ceramic mural art, and the design principles in ceramic mural art. The experimental results show that there are significant differences in the artistic design principles of ceramic murals $(P<0.05)$, and there are significant differences in the artistic design principles of ceramic murals $(P<0.05)$. Therefore, the artistic design principles of modern ceramic murals should mainly follow elegant and prominent forms.
\end{abstract}

\section{Introduction}

The birth of reinforced concrete has completely changed people's living environment and public space, making people's buildings more compact for indoor use and significantly reducing the threat to human life from natural disasters such as earthquakes and fires [1-13]. However, cold concrete buildings also make the public space environment and living environment monotonous, making them lose their personal and regional characteristics [14-26]. The development of modern Chinese ceramic murals is relatively slow [27-39]. As western artists increasingly use ceramic murals to decorate public places and environments, they have achieved good results [40-52]. The development of household ceramic murals is very rapid, and many ceramic murals with high artistic value are accepted by the public [52-58]. As an essential means of decorating public spaces, ceramic murals have attracted more and more attention. The research on ceramic murals can create a harmonious public space environment that meets people's material and spiritual needs [59-62]. It has become a hot topic of discussion and research and is of great significance to art and engineering [63-67]. Ebnali et al. propose an augmented reality computer vision-based technique in order to communicate automation reliability in partially automated driving vehicles. Digital image processing with augmented reality help to reduce the reaction time, which improve users' safety while the system is on the lower reliability mode [68]. In [69], the authors propose a deep-learning/computer-vision-based method for the analysis of the human hand, which automatically detects and segments out different hand semantic parts such as fingers from the input image. The proposed method learns to perform the task without the need for any segmentation labels at the training time.

With the development of urbanization and the rapid development of the construction industry, more and more public environments need decorative design, enabling ceramic artists to participate in the environmental art of public 
spaces, thereby linking art and technology, and art and design are approaching. Chen et al. proposed that the rule of form applied to ceramic mural design has important practical significance. He mainly discusses the application of the plane composition, three-dimensional composition, color composition, and texture effect in the design of ceramic murals through the analysis and research of the beauty rules of the form and the design of ceramic murals [70]. Kiedrowski believes that constitutional art is a widely influential art form in modern visual art. It enriches the formal language of modern mural design and broadens the expression of visual aesthetics, which has an important influence on the development of modern murals [71]. Wang et al. pointed out that the objective life of the society determines the art of each era at that time. Once society changes, the art that reflects this era cannot fail to produce corresponding changes. The old art has become history as a product of the previous era, and new art will also emerge with the development of the times [72]. In [73], the author proposed using two image processing techniques (Canny edge detection and Hough line transform) combined with the Mask R-CNN model to measure the depth of flood in images of traffic signs. In [74], the author proposed using the Canny edge detection and Hough transform image processing techniques combined with $A *$ search route optimization and distance decay function to determine the shortest flood-free route for citizens transiting in flood events.

The history of Chinese ceramics is the largest globally, and Chinese translation can show that ceramics are significant to China. At present, ceramic murals have been widely used in architectural environment decoration worldwide, but for China, it needs to be developed and improved. Compared with the development of ceramic murals globally, the development of ceramic murals in China is still in its infancy, but artists increasingly use the decoration of ceramic murals in public places. By interpreting the status quo of visual communication, $\mathrm{A} \mathrm{H} \mathrm{T}$ helps readers create artworks with a unique artistic vision and a clearer understanding of visual communication phenomena in society [75]. Xi et al. introduced the development process of Chinese subway mural art, summarized valuable experiences from the historical development and creation, and analyzed the future development prospects of Chinese subway mural art [76]. Rosario introduces a group of famous contemporary ceramic artists and their works, outlines their art forms and style characteristics, and demonstrates the form characteristics of ceramic murals in the public environment in the form of case appreciation and analysis [77]. This research proposal has enabled ceramic art to reach a certain level, but ceramic art has not been fully reflected in practical applications, and its practicability is not high.

Ceramic mural art is a kind of visual art that can reflect the urban culture and humanistic spirit. It is an art form with both aesthetics and functionality. The research of this subject starts with the universality of ceramic mural art, analyzes the ceramic mural art in major domestic cities, summarizes the language and design principles of visual communication, and summarizes the visual communication form suitable for ceramic mural art. The innovation of this paper is to compare the edge detection operators in the experimental part, analyze the advantages and disadvantages of each edge detection operator, and choose the edge detection operator suitable for ceramic mural image detection. Finally, the optimal threshold is obtained through the iterative threshold segmentation method, and the image is binarized, the roundness index is used to distinguish the genuine and the inferior products, and finally, the classification is realized.

\section{Visual Form of Ceramic Mural Art Based on Computer Vision Technology}

\subsection{Digital Image Processing Technology}

2.1.1. Digital Image Processing Technology. With the rapid development of computer technology, digital image processing technology will continue to mature. The current decline in the cost of computer equipment, the expansion of broadband Internet communications on the Internet, the proliferation of image digitization and imaging equipment, and the implementation of low-cost digital image processing systems have created unprecedented opportunities for the continuous development of digital processing technology $[78,79]$.

2.1.2. Digital Image Processing, Recognition, and Understanding. Image processing is the use of computer systems to process digital images for various purposes. Image processing in time aims to improve image quality and use people as objects to improve people's visual effects. In image editing, the input image quality is poor, and the output image quality is higher $[80,81]$. There is also a type of image processing that uses machines as objects. The purpose of processing is to allow the machine or computer to recognize the target, which is called image recognition automatically.

\subsubsection{Main Research Contents of Digital Image Processing.} The recently studied waveform transformation has good detection characteristics in time and frequency and has many practical applications in image processing. Image enhancement and restoration aim to enhance the image quality to highlight the region of interest in the image. Although many edge extraction and region segmentation methods have been studied, no practical method applies to various images. Therefore, the research on image segmentation continues to deepen, which is also one of the hotspots of current image processing research $[82,83]$.

\subsubsection{Process of Ceramic Mural Art Image Processing.} The digital camera images are stored as "frames" in the memory, and the application can export and process any "frame" data at any time. The primary task of a digital image processing system is to use a specific algorithm to determine the required information from a specific "frame" of the 
image. There are usually many methods to achieve the goal, but the results and efficiency obtained using different algorithms may be very different $[84,85]$. The basic process of processing ceramic mural art images is shown in Figure 1.

2.2. Image Processing Technology of Ceramic Murals. First of all, ceramic murals have a horizontal extension of the architectural space. Due to the structural layout of the entire building, some building spaces may be relatively small. Usually, hanging a bright mirror on the wall of the room will make people have a visual illusion, feeling that the size of the room has doubled. In the same way, artists can create a sensory ideal space environment through various sensory effects of ceramic murals [86]. The artist makes full use of the space changes, starting from the content of the ceramic mural itself, using light and dark contrast, virtual and real contrast, size contrast, etc., to make full use of the visual illusion of the human eye to achieve the purpose of extending the architectural space.

Secondly, ceramic murals have a horizontal contraction effect on the architectural space. The narrow architectural space environment makes people feel anxious, so people yearn for a spacious space, which makes people feel comfortable. However, things must be reversed; too empty and open space will also make people feel lonely and indifferent. This kind of "spaciousness" has turned into a disadvantage [87]. Artists can change people's feelings of overly spacious space environment through human visual senses. People's attention is attracted by the contrast of different forms of ceramic murals and the expression of the proportions of the ceramic murals. People's visual focus will be on the ceramic murals as soon as they enter the space environment, ignoring other environmental factors. To successfully achieve these, one must be familiar with the overall public space environment, understand people's psychology, and be good at discovering the central point of people's vision. Among them, image preprocessing, edge detection, filtering, and image binarization are required, specifically as follows:

(1) Image preprocessing: the first step of image processing is generally to preprocess the image. Image preprocessing mainly completes the fair compensation and smoothing of the target image. Its ultimate goal is to provide as adequate image data as possible for subsequent processing:

$$
\begin{aligned}
\Delta & =d\left(1+\frac{1}{M}\right), \\
d_{2} & =\frac{l_{1}+l_{2}}{l_{1}} d_{1}, \\
\Delta d_{2} & =\frac{l_{1}+l_{2}}{l_{1}} \Delta d_{1} .
\end{aligned}
$$

For a target composed of an infinite number of points, a superposition of countless enlarged ring holes is formed on the image surface. These superimposed ring holes are called coded images [88]. Suppose the target function is $o(x, y), h(x, y)$ is the point spread function of the annular coded aperture system, and $n(x, y)$ is the irrelevant noise function of the system, then the image function $i(x, y)$ formed by the coded aperture camera is as follows:

$$
i(x, y)=o(x, y) * h(x, y)+n(x, y) .
$$

In the formula, $*$ is the convolution symbol, and the Fourier transform of the above formula can obtain the frequency spectrum distribution as follows:

$I(u, v)=O(u, v) H(u, v)+N(u, v)$,

$O^{\prime}(u, v)=H^{-1}(u, v) I(u, v)=O(u, v)+H^{-1}(u, v) N(u, v)$.

However, in many problems, $H$ has a zero point or has a small value in some areas; that is, there is a singular or ill-conditioned problem, or there is no inverse transformation, or has a severe amplification effect on noise, so the inverse filtering method is beneficial in practical applications [89].

(2) Edge detection: the gradient $f(x, y)$ in the direction of $\theta$ along $\gamma$ is defined as follows:

$$
\frac{\partial f}{\partial \gamma}=\frac{\partial f}{\partial x} \frac{\partial x}{\partial \gamma}+\frac{\partial f}{\partial y} \frac{\partial y}{\partial \gamma}=f_{x} \cos \theta+f_{y} \sin \theta
$$

The condition for obtaining the maximum value of $\partial f / \partial \gamma$ is $(\partial(\partial f / \partial \gamma) / \partial \theta)=0$, namely:

$$
\begin{aligned}
-f_{x} \sin \theta_{g}+f_{y} \cos \theta_{g} & =0, \\
\theta_{g} & =\arctan \frac{f_{y}}{f_{x}}, \\
g & =\left(\frac{\partial f}{\partial \gamma}\right)_{\max }=\sqrt{f_{x}^{2}+f_{y}^{2}} .
\end{aligned}
$$

The maximum gradient $g$ is the image edge detection value.

(3) Filter: filtering is to find a filter with a transfer function of $H_{w}(u, v)$, so that the mean square error between the recovered target estimate $o^{\prime}(x, y)$ and the real $o(x, y)$ is the smallest, namely:

$$
\begin{aligned}
E\left\{\left[o(x, y)-o^{\prime}(x, y)\right]^{2}\right\} & =\min , \\
H_{w}(u, v) & =\frac{H^{*}(u, v)}{|H(u, v)|^{2}+S_{n}(u, v) / S_{o}(u, v)} .
\end{aligned}
$$

Among them $H^{*}(u, v)$ is the complex conjugate of the transfer function of the coded aperture imaging system, and $S_{o}(u, v)$ and $S_{n}(u, v)$ are the power spectral density of the target image and noise, 


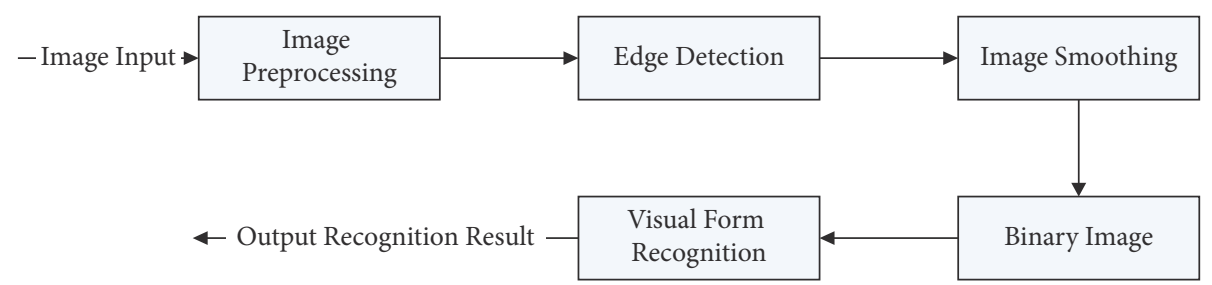

FIgURE 1: Flowchart of ceramic mural art image processing.

respectively; then the recovered target estimate is as follows:

$O^{\prime}(u, v)=H_{w}(u, v) \cdot I(u, v)=\frac{H^{*}(u, v) \cdot I(u, v)}{|H(u, v)|^{2}+S_{n}(u, v) / S_{o}(u, v)}$.

For calculation convenience, $S_{n}(u, v) / S_{o}(u, v)$ it can be set to a particular empirical value $\varepsilon$ according to the different processing objects, namely:

$$
\begin{aligned}
H_{w}(u, v) & =\frac{H^{*}(u, v)}{|H(u, v)|^{2}+\varepsilon}, \\
O^{\prime}(u, v) & =\frac{H^{*}(u, v)}{|H(u, v)|^{2}+\varepsilon} \cdot I(u, v) \approx O(u, v)+N^{\prime}(u, v) .
\end{aligned}
$$

Do the inverse Fourier transform of the above formula, and the reconstructed target image is obtained as follows:

$$
o^{\prime}(x, y) \approx o(x, y)+n^{\prime}(x, y) .
$$

(4) Binary image: the greater the variance between the background and the foreground, the more significant the difference between the two parts, so when the variance between the two parts reaches the maximum, this threshold $T$ is the best threshold of the maximum variance method [68]. The variance between the two groups is expressed as follows:

$$
\begin{aligned}
\delta^{2}(T) & =\omega_{0}\left(\mu_{1}+\mu\right)^{2}+\omega_{1}\left(\mu_{2}+\mu\right)^{2}=\omega_{0} \omega_{1}\left(\mu_{2}-\mu_{1}\right) \\
& =\frac{[\mu \omega(T)-\mu(T)]^{2}}{\omega(t)[1-\mu(T)]} .
\end{aligned}
$$

Among them $\mu_{2}$ are the probabilities generated by the two parts and $\mu$ is the image's overall gray value [90]. Let $x(t)$ be a square-integrable function, denoted as $x(t) \in L^{2}(R)$, and $\psi(t)$ is a function called basic wavelet, then:

$$
\mathrm{WT}_{x}(a, k)=\frac{1}{\sqrt{a}} \int_{-\infty}^{+\infty} x(t) \psi^{*}\left(\frac{1-k}{a}\right) \mathrm{d} t=\left\langle x(t), \psi_{o k}(t)\right\rangle .
$$

Wavelet transforms called $x(t)$. among them,

$$
\psi_{o k}(t)=\frac{1}{\sqrt{a}} \psi\left(\frac{t-k}{a}\right)
$$

is the displacement and scale expansion of the basic wavelet. In addition, $a$ is the scale factor and $k$ reflects the displacement. The symbol $\langle x, y\rangle$ represents the inner product, and the equivalent frequency domain representation is as follows:

$$
\mathrm{WT}_{x}(a, k)=\frac{\sqrt{a}}{2 \pi} \int_{-\infty}^{+\infty} X(\bowtie) \Psi^{*}(a \bowtie) e^{j ळ \pi} \mathrm{d} \omega
$$

where $X(\Phi)$ and $\Psi^{*}(a \varpi)$ are the Fourier transform of $x(t)$ and $\chi(t)$, respectively [91].

\subsection{Relationship between Ceramic Murals and Public Space Environment}

2.3.1. Ceramic Murals Exist Based on the Public Space Environment. The mural made of ceramic materials alone does not have any meaning and value. The ceramic murals exist for a specific public space environment. Its meaning depends on the overall atmosphere of the public space environment, and its manifestation and physical existence depend on the public space environment [91, 92]. Ceramic murals exist based on the large environment of public space. Since its creation, the ceramic mural has not existed as an independent thing; it exists to embellish or beautify the space. That is to say, ceramic murals must match the public space environment in which they are located. This is necessary for ceramic murals to play a good role in beautifying the public space environment. Regardless of how colorful the ceramic mural works are, if it is in harmony with the environment in which it is just completed, even if it does not look so eye-catching, the overall public space environment after it is embellished will often reach unexpected effect [93].

2.3.2. The Public Space Environment Restricts Ceramic Murals. The public space environment is not only the carrier on which the ceramic murals attach, but it also restricts the ceramic murals. The wall shape of the public space environment will restrict ceramic murals. The previous section has discussed the dependence of the physical existence of ceramic murals on the building walls in the public space environment. The physical form of ceramic murals must first meet the requirements of the public space environment. This is a sufficient condition for ceramic 
murals to exist in the public space environment $[94,95]$. At the same time, it also caused restrictions on ceramic murals in the public space environment. The shape of the wall in the public space environment is not fixed; it changes with the overall structure of the public space. Its size changes with the size of the entire building structure. It can be a regular rectangle or an irregular arc, a plane, or a threedimensional structure composed of several planes. The creation of ceramic murals is developed based on these external constraints.

2.3.3. Space Adjustment of Ceramic Murals to the Public Environment. The significance of ceramic murals is to embellish and beautify the public space environment. Successful ceramic mural works will give the finishing touch to the public space environment. The artist uses human visual effects and the expression technique of ceramic murals to even make up for certain flaws in the public space environment. Ceramic murals play a role in the horizontal extension of the architectural space. Due to the influence of the layout of the entire building structure, some building spaces may be relatively small [96, 97]. Usually, hanging a bright mirror on the wall of the room will make people have a visual illusion, feeling that the size of the room has doubled. In the same way, artists can create a sensory ideal space environment through various sensory effects of ceramic murals. The artist makes full use of the space changes, starting from the content of the ceramic mural itself, using light and dark contrast, virtual and real contrast, size contrast, etc., to make full use of the visual illusion of the human eye to achieve the purpose of extending the architectural space.

Successful ceramic murals are an indispensable part of the public space environment. Successful artists are good at using the elements of the architectural space environment to achieve the overall beauty of their ceramic mural art [98-101]. The form and technique of ceramic mural painting itself are only many means to embody the artist's creative ideas. Only by combining the various elements of the architectural space environment and making them a way to express the ideas of ceramic murals can the unity and coordination of ceramic murals and architectural space environment be genuinely achieved [102-107].

2.4. Ceramic Art Applied to Landscape Design. As one of the public language arts, ceramic art has formed a unique image, symbol, and even an ignorant concept into the field of public landscape design due to its unique material properties and historical and cultural properties. The ceramic art involved in this article is mainly from ceramics. The material and language characteristics of the material itself and the application of the abstract language of ceramic art to describe the landscape space are intended to find a way to not only create a dialogue between the ceramic art creator and the public but also create a dialogue between the public landscape space and the public-compatibility language.

\section{Visual Form of Ceramic Mural Art Based on Computer Vision Technology}

3.1. System Architecture Design. A ceramic mural art detection system was written with $\mathrm{VC}++$ based on much research on image processing applications. The software adopts a modular design, and the image processing functions are classified by function, so it has nothing to do with the software interface. The software interface can call specific image processing functions in various ways and display the images before and after processing in the designated area. The system software mainly completes the following tasks: connecting digital cameras, saving images, image preprocessing, image segmentation processing, image feature extraction and classification, and stepping motor control. The system flow software block diagram is shown in Figure 2.

3.2. Test Subject. This article uses a ceramic mural art vision system based on computer vision technology. It selectively enters 4000 pieces of various ceramic murals and classifies and analyzes them. Each ceramic mural has multiple attributes. Here, we analyze the composition in ceramic mural art, the graphics in ceramic mural art, the color in ceramic mural art, the scale in ceramic mural art, the lighting in ceramic mural art, and the design principles in ceramic mural art. Based on the above six indicators, we designed relevant questionnaires by searching many documents and distributing the questionnaires to the masses. Here we distribute them according to the approximate age groups. Each age group distributes 100 questionnaires. All questions are divided into 5 Levels (beautiful, fair, decent, abstract, and ugly). The questionnaires issued this time are sent back on the spot after they are written. The questionnaire recovery rate is $100 \%$. There are no open questions in all the questionnaires, so the efficiency is $100 \%$.

3.3. Experimental Method. In the preexperiment stage, we need to input extensive sample data and classify and analyze the ceramic mural art visual system based on computer vision technology. We also need to query a large amount of literature data to design-related questionnaires.

In the experimental stage, our experimental object is the artistic visual form of ceramic murals, and the data source is the questionnaire issued and recovered. Here we are issuing questionnaires by age group to reduce significant differences.

In the postexperiment stage, we collected statistics on the collected questionnaires. We followed the composition in ceramic mural art, graphics in ceramic mural art, color in ceramic mural art, scale in ceramic mural art, lighting in ceramic mural art, and the six indicators of design principles in ceramic mural art and related knowledge analyze these data to get a conclusion.

3.4. Data Collection. There are many data standard processing methods, but different data standardization methods will have a particular impact on the evaluation results of the system. For the positive indicator standardization method, 


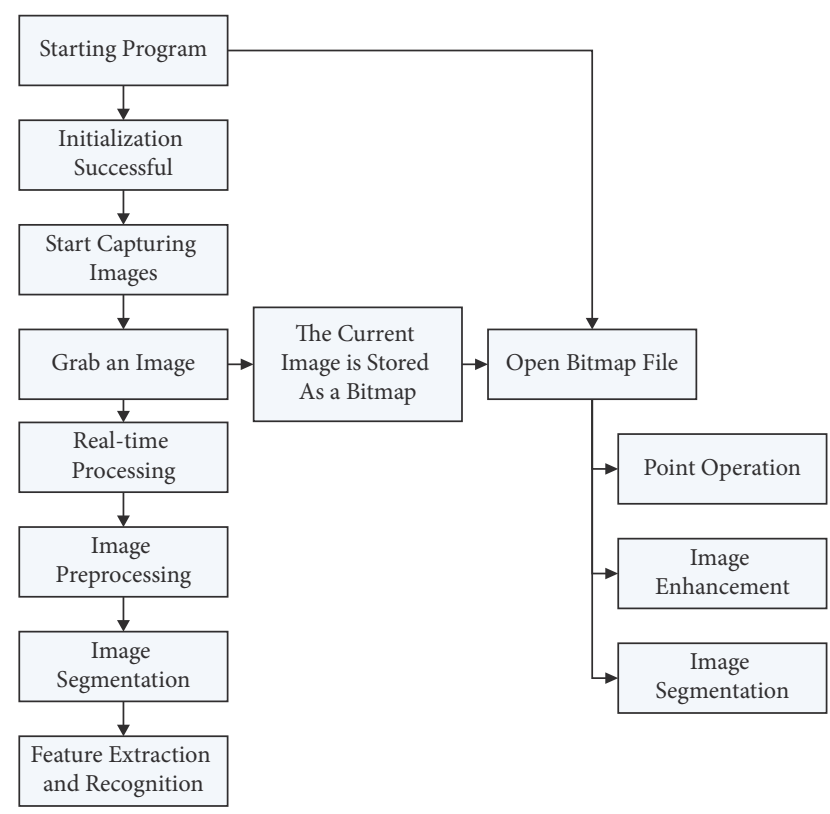

FIgURE 2: Flowchart of ceramic mural art detection software.

$$
y_{i j}=\frac{x_{i j}-\min \left\{x_{i j}\right\}}{\max \left\{x_{i j}\right\}-\min \left\{x_{i j}\right\}} .
$$

For negative index standardization methods,

$$
y_{i j}=\frac{\max \left\{x_{i j}\right\}-x_{i j}}{\max \left\{x_{i j}\right\}-\min \left\{x_{i j}\right\}} .
$$

3.5. Statistical Data Processing Method. SPSS23.0 software was used for data processing, and the count data were expressed in percentage, $k$ is the number of data in this experiment, $\sigma^{2}$ is the variance of all survey results, and $P<0.05$ indicates that the difference is statistically significant. The formula for calculating reliability is shown in the following equation:

$$
a=\frac{k}{k-1}\left(1-\frac{\sum \sigma_{i}^{2}}{\sigma^{2}}\right)
$$

3.6. Evaluation Index System Based on Index Reliability Testing. Reliability refers to the stability and reliability of the questionnaire. This article adopts the $\alpha$ coefficient method created by L. J. Cronbach. Reliability Analysis can obtain the $\alpha$ coefficient in SPSS software. It is generally believed that the $\alpha$ coefficient above 0.8 indicates that the effect of the index set is perfect, and above 0.7 is also acceptable. Here, we analyze the reliability of each type of object, and the reliability index we choose for each type of object is slightly different. The results are shown in Table 1.

It can be seen from Table 1 that the composition in the ceramic mural art, the graphics in the ceramic mural art, the color in the ceramic mural art, the scale in the ceramic mural art, the lighting in the ceramic mural art, and the design principle indicators in the ceramic mural art the influence of the obtained data on this experiment are acceptable $(\alpha>0.7)$. The design principles in the artistic design of modern ceramic murals should mainly follow the principles of graceful form, highlighting regional culture, people-oriented, and green environmental protection. Teachers can reasonably use rational design principles to design ceramic mural art that is more in line with people's aesthetic needs and the development of the times.

\subsection{Visual Communication Language in Ceramic Mural Art}

3.7.1. Composition of the Ceramic Mural Art. In the composition management of mural paintings, images in multiple spaces simultaneously are often combined on one screen, or images from multiple times in the same space are also combined on one screen, or images from multiple times are combined on one screen. Images and images in multiple spaces are combined on one screen, and the results are shown in Table 2. We make a histogram based on this result, as shown in Figure 3.

Through the paired sample $T$-test, it can be found that after the experiment, the $P$ value of each age group on the composition score of the ceramic mural art is less than 0.05 . There is a significant difference; the $P$ value of each composition index in the ceramic mural art is also less than 0.05 . Significant differences explain how to organize the picture structure and form the picture's integrity, and the environment is the most important. These characteristics help the ceramic mural art spread better and better display the charm of the mural art. The specific situation is shown in Figure 3.

3.7.2. Graphics in the Ceramic Mural Art. Graphics are not just a description of the objective world. Designers can use graphics to create a sense of form, produce more profound visual effects, stimulate people's senses, and stimulate people's pursuit of beauty. Graphic language carries a rich accumulation of content and is a highly symbolic visual language. The results are shown in Table 3. We make a bar graph based on this result, as shown in Figure 4.

Through the paired sample $T$-test, it can be found that after the end of the experiment, there is a significant difference in the $P$ value of each age group on the graphic score of the ceramic mural art, which is less than 0.05 ; the $P$ value of each index in the ceramic mural art is also less than 0.05. The significant difference explains how to flexibly master the arrangement method of the visual elements of subway murals and how to spread the mural information better and more effectively require the collective efforts of designers. They must have some insights into inheritance and development and persevere in subway murals, going farther and farther on the creative road. The specific situation is shown in Figure 4.

3.7.3. Colors in the Ceramic Mural Art. The application of color symbols tends to pay more attention to its symbolic meaning. The role of symbolic color and human vision will 
TABLE 1: Summary table of reliability test results.

\begin{tabular}{lcc}
\hline Category & Index combination & Alpha coefficient $(\alpha)$ \\
\hline \multirow{2}{*}{ Composition of the mural } & Centrosymmetric & 0.8632 \\
& Scattered reconstruction & Full belly \\
& Geometric segmentation & Specific description \\
Mural graphics & Abstract representation & Image extension \\
& Graphic animation & 0.7456 \\
\hline \multirow{2}{*}{ The color of the mural } & Warm tones & 0.7319 \\
& Cool colors & Neutral tones \\
\hline & Front side light & Backlight \\
Image lighting & Top light & Natural light \\
\end{tabular}

TABLE 2: Data table of composition scoring in ceramic mural art for each age group.

\begin{tabular}{lccccc}
\hline Year & Beautiful & General & Passable & Abstract & Ugly \\
\hline 8-18 years & 21 & 21 & 29 & 20 & 9 \\
19-28 years & 16 & 22 & 30 & 28 & 19 \\
29-38 years & 18 & 24 & 34 & 17 & 5 \\
39-48 years & 17 & 29 & 28 & 11 & 9 \\
Over 49 & 14 & 28 & 36 & 0.005 \\
$P$ & 0.013 & 0.005 & 0.005 & 11 \\
\hline
\end{tabular}

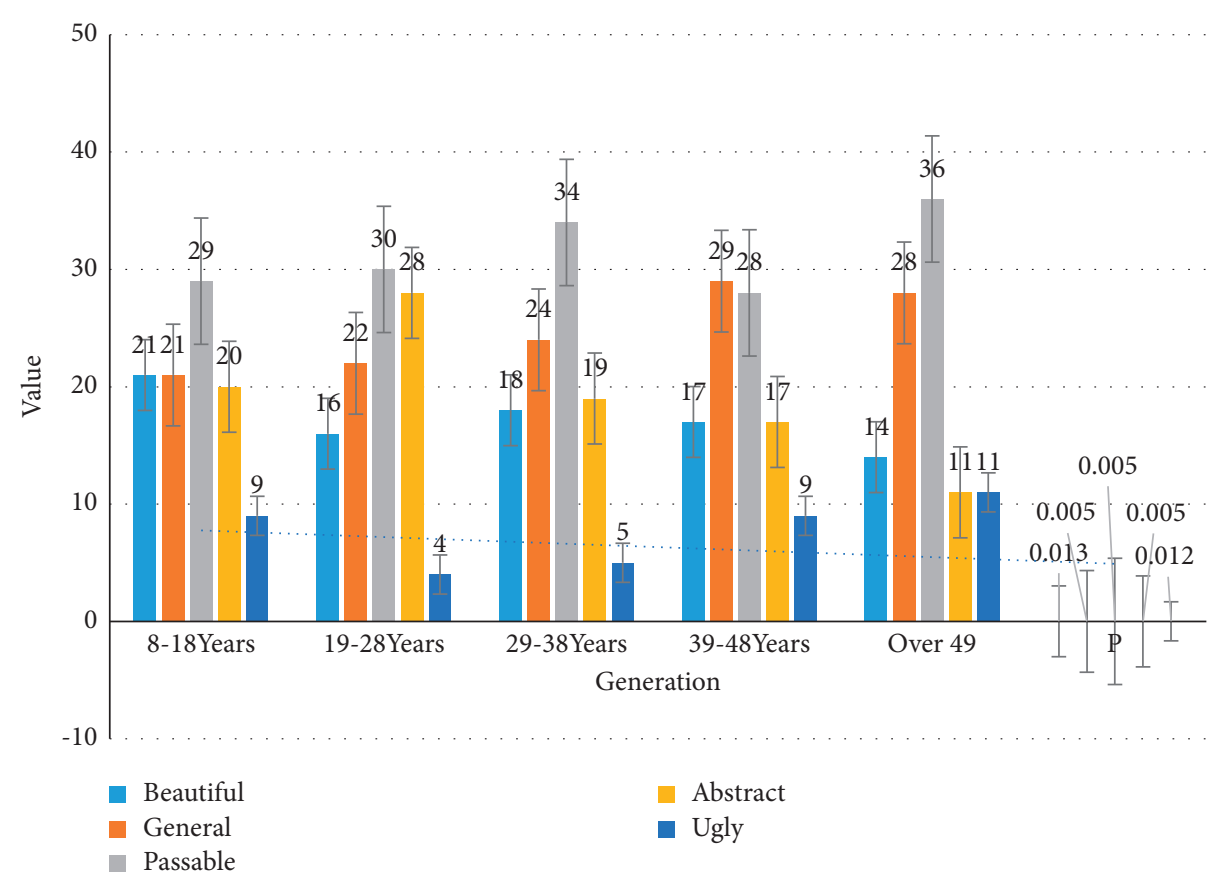

FIGURE 3: Grading chart of composition in ceramic mural art by age groups.

produce strong psychological induction, stimulating human emotion and imagination. As a form of visual language, the color corresponds to real objects, and human spirit and emotion are connected. The results are shown in Table 4 . We make a combination diagram based on this result, as shown in Figure 5.
Through the paired sample $T$-test, it can be found that after the experiment, the $P$ value of each age group on the color score of ceramic mural art is less than 0.05 ; there is a significant difference; the $P$ value of each index of the color in ceramic mural art is also less than 0.05 . The significant difference shows that only the existence of color contrast can 
TABLE 3: Data table of scoring figures in ceramic mural art by age groups.

\begin{tabular}{lccccc}
\hline Year & Beautiful & General & Passable & Abstract & Ugly \\
\hline 8-18 years & 25 & 28 & 24 & 14 & 15 \\
19-28 years & 30 & 25 & 27 & 35 & 19 \\
29-38 years & 19 & 22 & 30 & 17 & 15 \\
39-48 years & 17 & 18 & 29 & 11 & 18 \\
Over 49 & 8 & 30 & 0.001 & 22 \\
$P$ & 0.001 & 0.001 & & 0.001 & 0.001 \\
\hline
\end{tabular}

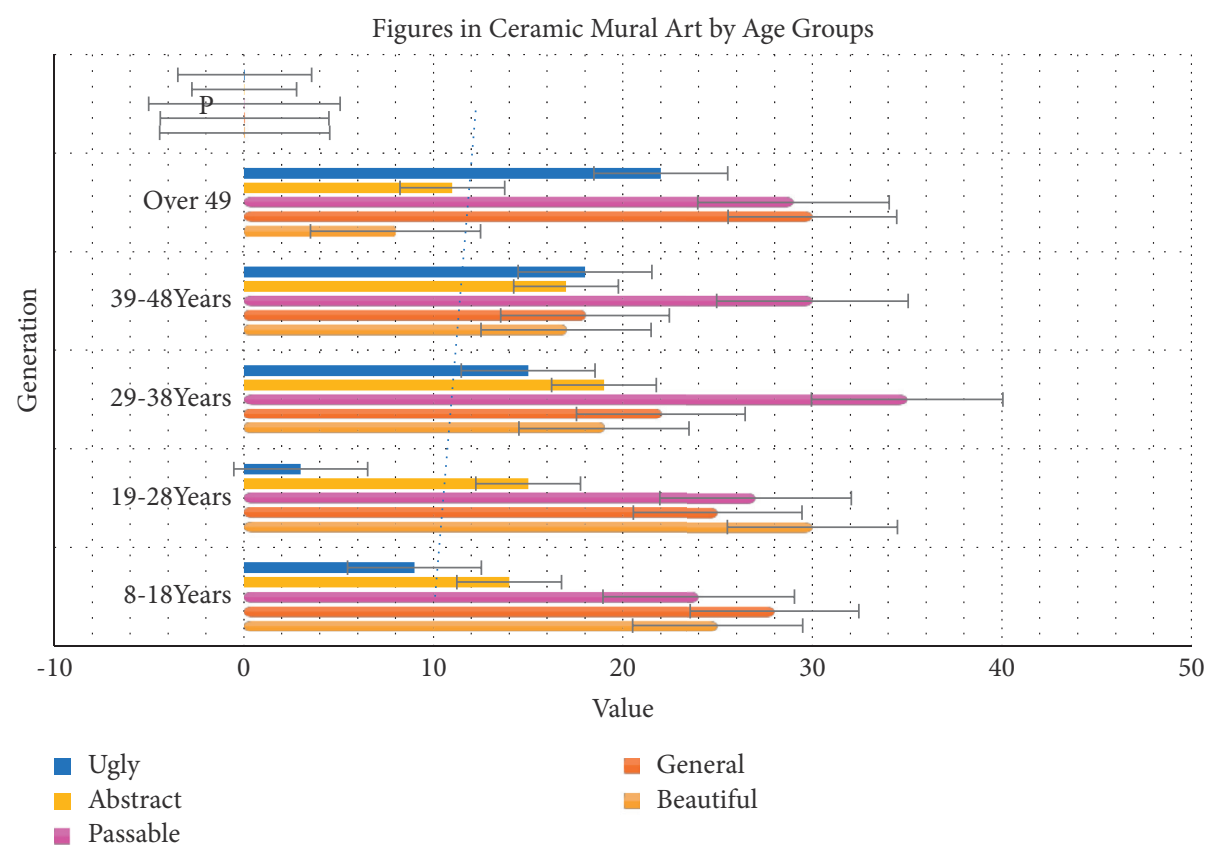

FIGURE 4: Grading chart of figures in ceramic mural art by age groups.

effectively spread. The strong contrast will quickly attract people's attention, and the weakened contrast can calm people's impetuous mood in the underground space. The specific situation is shown in Figure 5.

3.7.4. Scale in Ceramic Mural Art. The height and width of the subway mural art need to be determined according to the area of the underground space and the height and width of the wall so that the subway mural art is in harmony with the overall environmental space. The importance of scale is based on the other visual communication elements of the subway mural art. Above, the integration of scale and environment is the critical factor of visual aesthetics. The results are shown in Table 5 . We make a pie chart based on this result, as shown in Figure 6.

Through the paired sample $T$-test, it can be found that after the experiment, the $P$ value of each age group on the scale score of ceramic mural art is less than 0.05 and has a significant difference; the $P$ value of each index of the scale in ceramic mural art is also less than 0.05 . The significant difference indicates that the scale of ceramic mural art must not only be in harmony with the environmental space, but the ultimate principle is to follow the principle of being
TABle 4: Data table of color scoring in ceramic mural art for each age group.

\begin{tabular}{lccccc}
\hline Year & Beautiful & General & Passable & Abstract & Ugly \\
\hline 8-18 years & 21 & 33 & 21 & 13 & 12 \\
19-28 years & 26 & 27 & 25 & 12 & 10 \\
29-38 years & 15 & 25 & 30 & 16 & 14 \\
39-48 years & 17 & 20 & 33 & 10 & 20 \\
Over 49 & 10 & 24 & 27 & 18 & 21 \\
$P$ & 0.043 & 0.037 & 0.027 & 0.019 & 0.044 \\
\hline
\end{tabular}

people-oriented and fully consider the influence of the scale of the mural on people's psychology so that the subway mural art can indeed act an art enters people's vision and soul. The specific situation is shown in Figure 6.

3.7.5. Lighting in the Ceramic Mural Art. The role of lighting is an indispensable way of expression for subway mural art. The use of light can change the spacing effect, make up for the lack of space, create a space atmosphere, strengthen the environmental characteristics, and locate the characteristics of the place. The results are shown in Table 6 . We make a doughnut chart based on this result, as shown in Figure 7. 


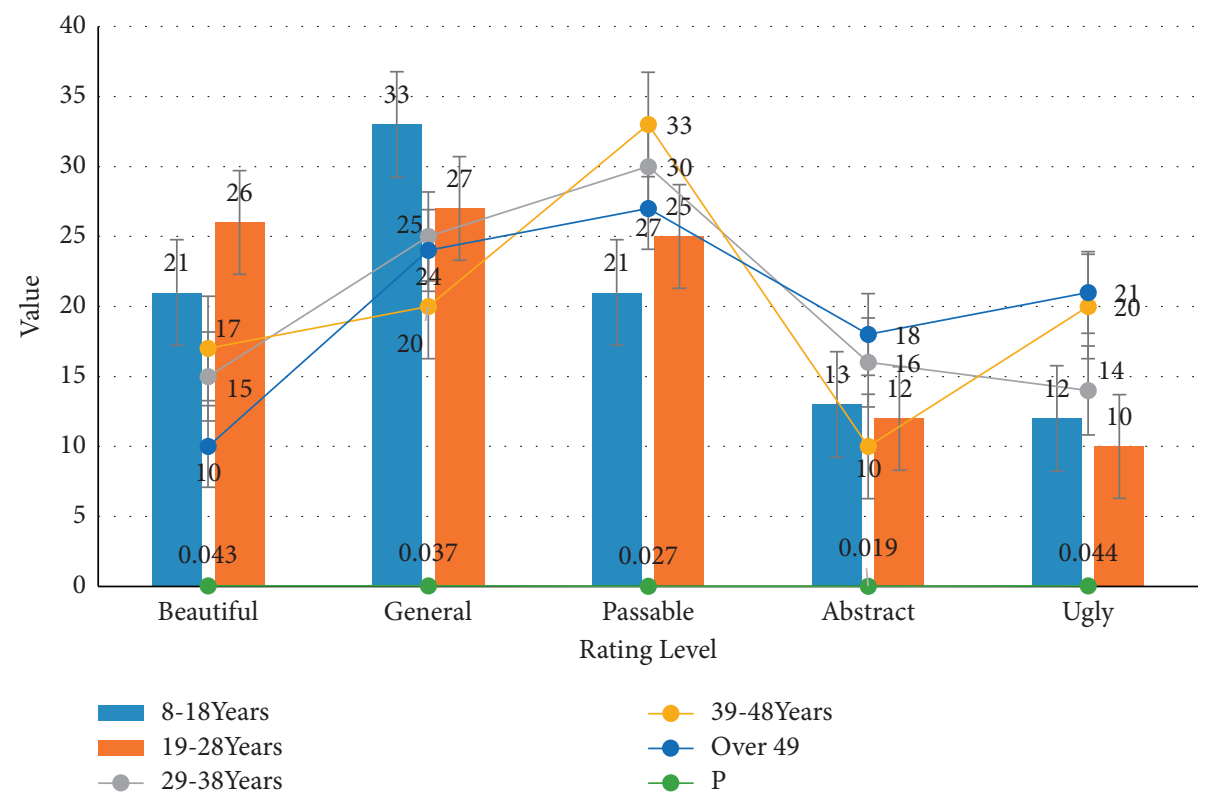

Figure 5: Color grading chart in the ceramic mural art by each age group.

TABle 5: Data table of the size scoring in ceramic mural art by age groups.

\begin{tabular}{lccccc}
\hline Year & Beautiful & General & Passable & Abstract & Ugly \\
\hline 8-18 years & 2.1 & 1.97 & 2.14 & 1.94 & 2.09 \\
19-28 years & 2.34 & 27 & 2.39 & 2.51 & 2.51 \\
29-38 years & 3.11 & 3.5 & 3.17 & 2.98 & 3.35 \\
39-48 years & 4.5 & 4.5 & 3.91 & 4.45 & 3.88 \\
Over 49 & 6.16 & 5.06 & 5.18 & 4.9 & 4.89 \\
$P$ & 0.005 & 0.005 & 0.005 & 0.010 & 0.019 \\
\hline
\end{tabular}

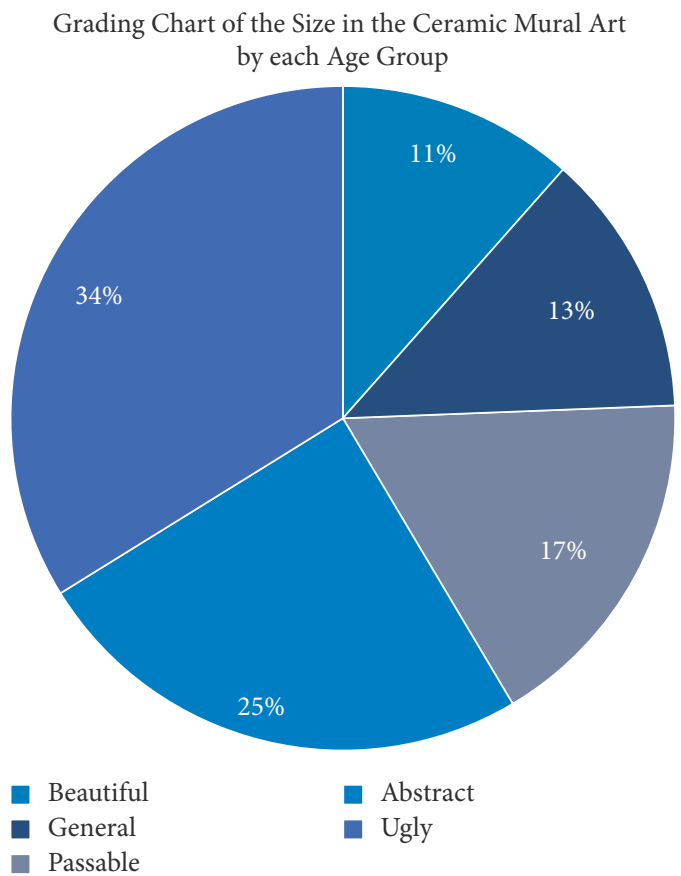

FIGURE 6: Grading chart of the size in the ceramic mural art by each age group.
Through the paired sample $T$-test, it can be found that after the experiment, the $P$ values of the lighting scores in the ceramic mural art are significantly different for each age group to be less than 0.05 ; the $P$ values of the lighting indicators in the ceramic mural art are also less than 0.05 . The significant difference shows that the most significant manifestation of the relationship between lighting and space environment is the effect of artificial lighting on the color performance of murals. The combination of light and color of ceramic mural art is complementary, and the use of light for murals must take complete account of the murals' content, color, material, and overall space environment so that the murals can form a harmonious main body and better with the environment. The specific situation is shown in Figure 7.

3.8. Comprehensive Design Principles in Ceramic Mural Art. In the design process, we must first follow the design principles of formal beauty. Secondly, for ceramic mural art, we must highlight the regional cultural characteristics, establish a people-oriented and environmentally friendly design concept, and combine contemporary expression techniques to perfect the ceramic mural art. Spread to the audience. The results are shown in Table 7 . We make a bar graph based on this result, as shown in Figure 8.

Figure 8 shows that there are significant differences in the design principles of ceramic mural art $(P<0.05)$, and the indicators of the design principles in ceramic mural art have significant differences $(P<0.05)$, so the modern ceramic mural art design principles should mainly follow the principles of graceful form, highlighting regional culture, people-oriented and green environmental protection, and rationally use rational design principles to design ceramic mural art that is more in line with people's aesthetic needs and the development of the times. 
TABLE 6: Data table of lighting scores in ceramic mural art by age groups.

\begin{tabular}{lcccrr}
\hline Rating level & Front side light & Backlight & Top light & Natural light & $P$ \\
\hline Beautiful & 3.23 & 3.46 & 2.81 & 4.48 & 3.04 \\
General & 4.46 & 4.12 & 4.95 & 5.92 & 0.008 \\
Passable & 5.03 & 4.83 & 5.3 & 5.41 & 0.008 \\
Abstract & 5.49 & 5.45 & 7.1 & 7.36 & 0.004 \\
Ugly & 7.4 & 7.13 & 0.001 \\
\hline
\end{tabular}

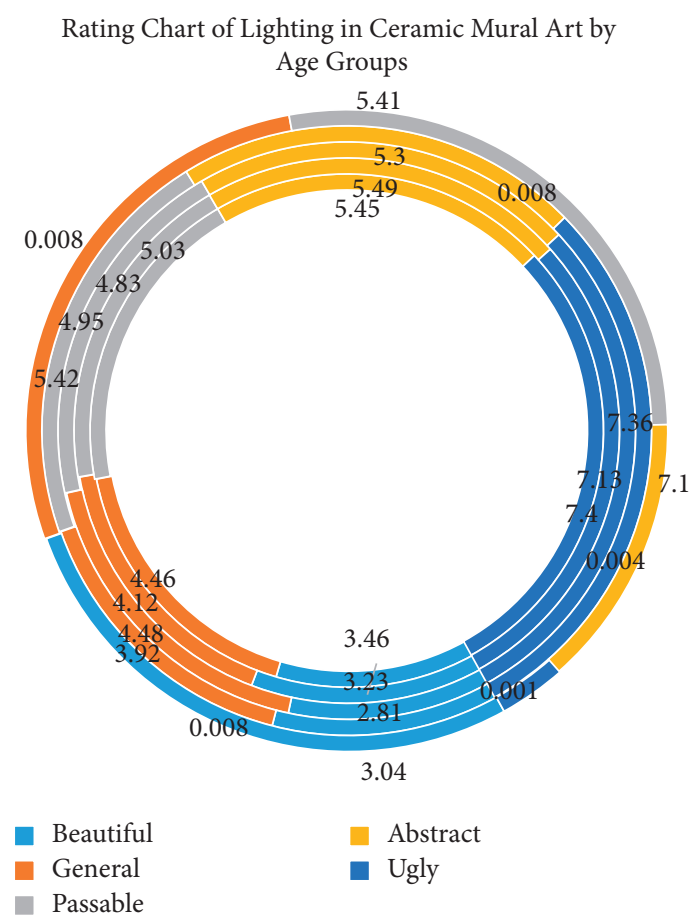

FIGURE 7: Rating chart of lighting in ceramic mural art by age groups.

TABLE 7: Comprehensive datasheet of design principles in ceramic mural art.

\begin{tabular}{|c|c|c|c|c|c|c|}
\hline & Beautiful & General & Passable & Abstract & Ugly & $P$ \\
\hline Beautiful form & 2.2 & 2.08 & 2.02 & 2.04 & 1.94 & 0.015 \\
\hline Symmetrical equilibrium & 2.34 & 2.38 & 2.35 & 2.62 & 2.41 & 0.018 \\
\hline Contrast unity & 2.99 & 3.36 & 3.33 & 3.02 & 2.97 & 0.005 \\
\hline Rhythm & 4.11 & 4.26 & 4.35 & 4.31 & 4.38 & 0.001 \\
\hline Scale & 5.46 & 4.81 & 4.95 & 5.31 & 5.22 & 0.004 \\
\hline Highlight regional culture & 5.18 & 5.01 & 5.39 & 5.1 & 5.38 & 0.004 \\
\hline People-oriented & 7.49 & 7.25 & 7.31 & 7.28 & 7.04 & 0.001 \\
\hline Green & 8.58 & 8.14 & 8.68 & 8.95 & 8.06 & 0.010 \\
\hline
\end{tabular}

\section{Discussion}

Architecture is the protagonist of public space environmental art, the main body and structural skeleton of public space, and its shape determines the main style of overall space environmental planning. As many new technologies and new materials are constantly being discovered, modern architecture uses these and new material technologies to create new aesthetic concepts. Ceramics is a traditional building material with a history of more than a thousand years. It regains new life through the combination of new technology and new ideas. The unique beauty, texture, color, texture, and potential of ceramics that can be produced without frame requirements and the history, tradition, culture, and other special charms it reflects are becoming more and more popular with artists and the public. This ancient and novel building material gradually becomes a creative material for some architects and artists to express and use. The use of machine vision technology to construct a ceramic mural art vision system can effectively find defects. The system has a simple structure and high-cost performance, which is of great significance in improving the inspection efficiency and reducing the inspectors' labor intensity. 


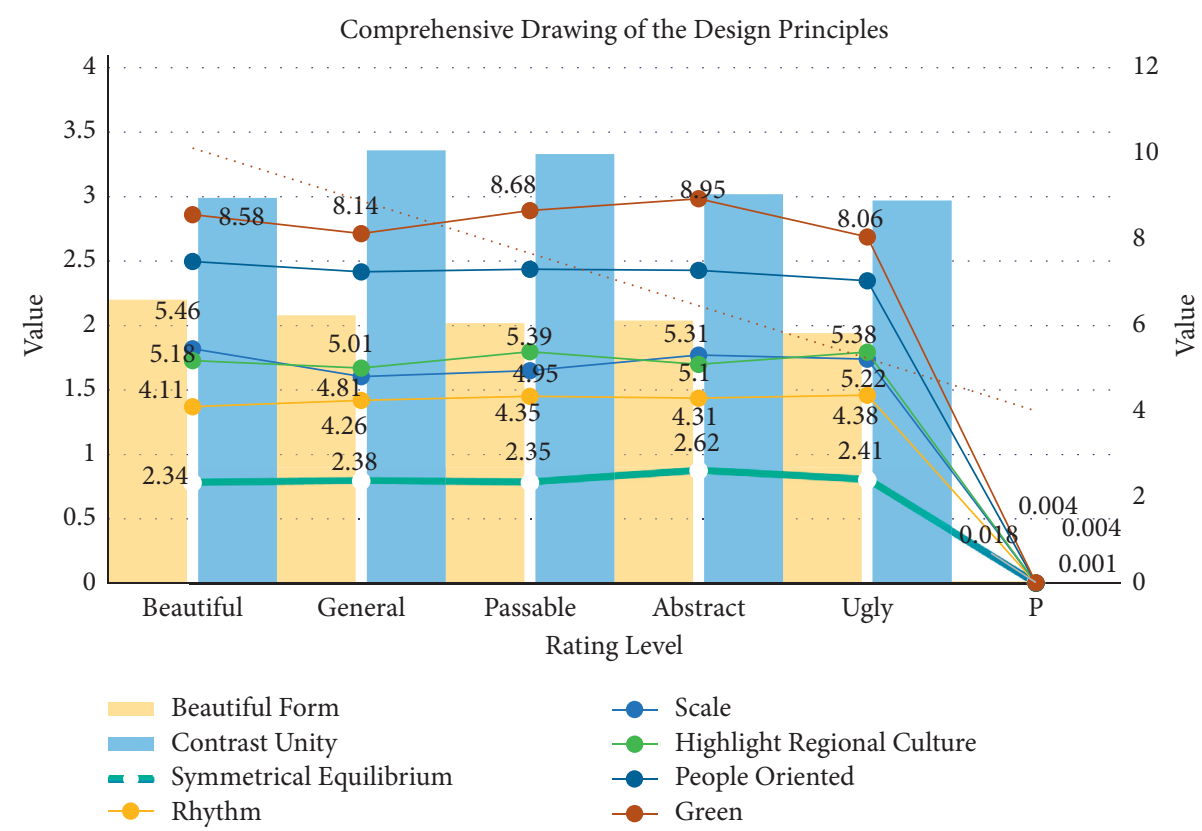

FIGURE 8: Comprehensive drawing of the design principles in ceramic mural art by various age groups.

Ceramic murals have high requirements for the artist's comprehensive ability. They need to have the most basic artistic ability and innovation ability but also need to have a deeper understanding of the traditional national cultural characteristics of the country and people's aesthetic characteristics. At the same time, they also need to have in-depth research on the characteristics of ceramic materials and have a detailed understanding of the structure of the architectural space environment. Modern ceramic murals must not only make ceramic murals coordinate with the physical structure and functional atmosphere of the public space environment but also help the entire public space environment to coordinate with the local humanistic environment and the entire natural environment, and strive to create a cultural and the social environment; human and natural environment is a unified environmental system. The image processing process that the ceramic mural art image must go through is studied. The median filter is used to smooth the image, which improves the image quality and the sharpness of the image. Through the experimental comparison of various edge detection operators, each edge detection is analyzed. The advantages and disadvantages of the operator and the edge detection operator suitable for ceramic mural art image detection are selected; finally, the optimal threshold is obtained through the iterative threshold segmentation method, the image is binarized, and the roundness index is used to correct the order products are judged and finally classified.

\section{Conclusions}

The improvement of modern people's aesthetic concepts, the diversification of modern home design styles, and the rise of modern art walls and cultural walls provide a realistic possibility for modern ceramic mural art to intervene in the home environment. The involvement of modern ceramic mural art in the modern home environment manifests the development of modern art and culture-the development of modern economy and technology guarantees modern ceramic mural art to intervene in the home environment. Modern ceramic mural art has deeper cultural connotations in both its art form and its artistic language, and it combines with the home environment space to build a unified art space. It is necessary to completely turn the public's thinking concepts and aesthetic inclination to art, and at the same time, it takes a certain amount of time and practical process. In addition to artistic creativity in artistic creation, ceramic artists should also master and study the various properties of mural materials. They should also have extensive knowledge and experience to explore murals and various objective environments, and people's subjective factors. However, the shortcomings of ceramic art are also reflected, such as lack of creativity and practicality.

\section{Data Availability}

There are no available data for this study.

\section{Conflicts of Interest}

The authors declare that they have no conflicts of interest.

\section{References}

[1] Z. Shen, F. Ding, and Y. Shi, "Digital forensics for recoloring via convolutional neural network," Computers, Materials \& Continua, vol. 62, no. 1, pp. 1-16, 2020. 
[2] S. Wang, T. Yue, and M. Abdel Wahab, "Multiscale analysis of the effect of debris on fretting wear process using a semiconcurrent method," Computers, Materials \& Continua, vol. 62 , no. 1, pp. 17-35, 2020.

[3] M. Abd El-Aziz and A. M. Aly, "Entropy generation for flow and heat transfer of sisko-fluid over an exponentially stretching surface," Computers, Materials \& Continua, vol. 62, no. 1, pp. 37-59, 2020.

[4] Q. Fan, Y. Zhang, and Z. Wang, "Improved teaching learning based optimization and its application in parameter estimation of solar cell models," Intelligent Automation \& Soft Computing, vol. 26, no. 1, pp. 1-12, 2020.

[5] M. Abdullah, S. A. Khan, M. Alenez, K. Almustafa, and W. Iqbal, "Application centric virtual machine placements to minimize bandwidth utilization in datacenters," Intelligent Automation \& Soft Computing, vol. 26, no. 1, pp. 13-25, 2020.

[6] D. Shi, S. Wang, Y. Cai, L. Chen, and C. Yuan, "Model predictive control for nonlinear energy management of a power split hybrid electric vehicle," Intelligent Automation \& Soft Computing, vol. 26, no. 1, pp. 27-39, 2020.

[7] B. Li, J. Yang, Y. Yang, C. Li, and Y. Zhang, "Sign language/ gesture recognition based on cumulative distribution density features using UWB radar," IEEE Transactions on Instrumentation and Measurement, vol. 70, pp. 1-13, 2021.

[8] N. Xiao, R. Xinyi, Z. Xiong, F. Xu, X. Zhang, and Q. Xu, “A diversity-based selfish node detection algorithm for socially aware networking," Journal of Signal Processing Systems, vol. 93, no. 7, pp. 811-825, 2021.

[9] S. Feng, C. Zuo, L. Zhang, T. Tao, Y. Hu, and W. Yin, "Calibration of fringe projection profilometry: a comparative review," Optics and Lasers in Engineering, vol. 143, Article ID 106622, 2021.

[10] G. D. Penna and S. Orefice, "Using spatial relations for qualitative specification of gestures," Computer Systems Science and Engineering, vol. 34, no. 6, pp. 325-338, 2019.

[11] H. Chen, A. A. Heidari, H. Chen, M. Wang, Z. Pan, and A. H. Gandomi, "Multi-population differential evolutionassisted harris hawks optimization: framework and case studies," Future Generation Computer Systems, vol. 111, pp. 175-198, 2020.

[12] M. Wang and H. Chen, "Chaotic multi-swarm whale optimizer boosted support vector machine for medical diagnosis," Applied Soft Computing, vol. 88, Article ID 105946, 2020.

[13] Y. Xu, H. Chen, J. Luo, Q. Zhang, S. Jiao, and X. Zhang, "Enhanced moth-flame optimizer with mutation strategy for global optimization," Information Sciences, vol. 492, pp. 181-203, 2019.

[14] X. Zhao, X. Zhang, Z. Cai, and X. Tian, "Chaos enhanced grey wolf optimization wrapped ELM for diagnosis of paraquat-poisoned patients," Computational Biology and Chemistry, vol. 78, pp. 481-490, 2019.

[15] C. Li, L. Hou, B. Y. Sharma, and H. Li, "Developing a new intelligent system for the diagnosis of tuberculous pleural effusion," Computer Methods and Programs in Biomedicine, vol. 153, pp. 211-225, 2018.

[16] M. Wang, H. Chen, B. Yang, and X. Zhao, "Toward an optimal kernel extreme learning machine using a chaotic moth-flame optimization strategy with applications in medical diagnoses," Neurocomputing, vol. 267, pp. 69-84, 2017.

[17] E. Yavuz, R. Yazıcı, M. Cem Kasapba, s1, and T. Tugay Bilgin, "Improving initial flattening of convex-shaped free-form mesh surface patches using a dynamic virtual boundary,"
Computer Systems Science and Engineering, vol. 34, no. 6, pp. 339-355, 2019.

[18] V. Pandey and P. Saini, "Application layer scheduling in cloud: fundamentals, review and research directions," Computer Systems Science and Engineering, vol. 34, no. 6, pp. 357-376, 2019.

[19] C. Liu, K. Li, and K. Li, “A game approach to multi-servers load balancing with load-dependent server availability consideration," IEEE Transactions on Cloud Computing, vol. 9, no. 1, pp. 1-13, 2021.

[20] C. Liu, K. Li, K. Li, and R. Buyya, "A new service mechanism for profit optimizations of a cloud provider and its users," IEEE Transactions on Cloud Computing, vol. 9, no. 1, pp. 14-26, 2021.

[21] G. Xiao, K. Li, Y. Chen, W. He, A. Y. Zomaya, and T. Li, "CASpMV: a customized and accelerative SpMV framework for the sunway taihulight," IEEE Transactions on Parallel and Distributed Systems, vol. 32, no. 1, pp. 131-146, 2021.

[22] M. Duan, K. Li, K. Li, and T. Qi, "A novel multi-task tensor correlation neural network for facial attribute prediction," ACM Transactions Intelligent Systems and Technology, vol. 12, no. 1, pp. 3-22, 2021.

[23] J. Feng, Z. Liu, and L. Feng, "Identifying opportunities for sustainable business models in manufacturing: application of patent analysis and generative topographic mapping," Sustainable Production and Consumption, vol. 27, pp. 509-522, 2021.

[24] C. Mi, Y. Huang, C. Fu, Z. Zhang, O. Postolache, and A. Authors, "Vision-based measurement: actualities and developing trends in automated container terminals," IEEE Instrumentation \& Measurement Magazine, vol. 24, no. 4, pp. 65-76, 2021.

[25] P. Wang, L. Wang, H. Leung, and G. Zhang, "Super-resolution mapping based on spatial-spectral correlation for spectral imagery," IEEE Transactions on Geoscience and Remote Sensing, vol. 59, no. 3, pp. 2256-2268, 2021.

[26] C. Chen, K. Li, S. G. Teo, X. Zou, K. Li, and Z. Zeng, "Citywide traffic flow prediction based on multiple gated spatio-temporal convolutional neural networks," ACM Transaction Knowledge Discovery Data, vol. 14, no. 4, pp. 1-23, 2020.

[27] X. Zhou, K. Li, Z. Yang, Y. Gao, and K. Li, "Efficient approaches to $k$ representative G-skyline queries," $A C M$ Transactions on Knowledge Discovery Data, vol. 14, no. 5, pp. 1-27, 2020.

[28] J. Wang, Y. Gao, X. Yin, F. Li, and H. J. Kim, “An enhanced PEGASIS algorithm with mobile sink support for wireless sensor networks," Wireless Communications and Mobile Computing, vol. 2018, Article ID 9472075, 9 pages, 2018.

[29] J. Xia, H. Chen, Q. Li, and M. Zhou, "Ultrasound-based differentiation of malignant and benign thyroid nodules: an extreme learning machine approach," Computer Methods and Programs in Biomedicine, vol. 147, pp. 37-49, 2017.

[30] H. L. Chen, G. Wang, C. Ma, Z. N. Cai, W. B. Liu, and S. J. Wang, "An efficient hybrid kernel extreme learning machine approach for early diagnosis of parkinson's disease," Neurocomputing, vol. 184, pp. 131-144, 2016.

[31] L. Shen, H. Chen, Z. Yu, and W. Kang, "Evolving support vector machines using fruit fly optimization for medical data classification," Knowledge-Based Systems, vol. 96, pp. 61-75, 2016.

[32] Z. Liao, J. Wang, S. Zhang, J. Cao, and G. Min, "Minimizing movement for target coverage and network connectivity in 
mobile sensor networks," IEEE Transactions on Parallel and Distributed Systems, vol. 26, no. 7, pp. 1971-1983, 2014.

[33] J. Wang, Y. Gao, W. Liu, A. K. Sangaiah, and H. J. Kim, “An intelligent data gathering schema with data fusion supported for mobile sink in wireless sensor networks," International Journal of Distributed Sensor Networks, vol. 15, no. 3, Article ID 1550147719839581, 2019.

[34] J. Zhang, X. Jin, J. Sun, J. Wang, and A. K. Sangaiah, “Spatial and semantic convolutional features for robust visual object tracking," Multimedia Tools and Applications, vol. 79, no. 21, pp. 15095-15115, 2020.

[35] F. Yu, L. Liu, L. Xiao, K. Li, and S. Cai, "A robust and fixedtime zeroing neural dynamics for computing time-variant nonlinear equation using a novel nonlinear activation function," Neurocomputing, vol. 350, pp. 108-116, 2019.

[36] X. Zenggang, T. Zhiwen, C. Xiaowen, Z. Xue-min, Z. Kaibin, and Y. Conghuan, "Research on image retrieval algorithm based on combination of color and shape features," Journal of Signal Processing Systems, vol. 93, no. 2-3, pp. 139-146, 2019.

[37] L. Wang, Y. Peng, Y. Xie, B. Chen, and Y. Du, "A new iteration regularization method for dynamic load identification of stochastic structures," Mechanical Systems and Signal Processing, vol. 156, Article ID 107586, 2021.

[38] T. Zhang, X. Wu, S. M. Shaheen, and J. Rinklebe, "Effects of microorganism-mediated inoculants on humification processes and phosphorus dynamics during the aerobic composting of swine manure," Journal of Hazardous Materials, vol. 416, Article ID 125738, 2021.

[39] J. Wang, X. Gu, W. Liu, A. K. Sangaiah, and H. J. Kim, “An empower hamilton loop based data collection algorithm with mobile agent for WSNs," Human-Centric Computing and Information Sciences, vol. 9, no. 1, pp. 1-14, 2019.

[40] L. Hu, G. Hong, J. Ma, X. Wang, and H. Chen, "An efficient machine learning approach for diagnosis of paraquat-poisoned patients," Computers in Biology and Medicine, vol. 59, pp. 116-124, 2015.

[41] X. Xu and H. L. Chen, "Adaptive computational chemotaxis based on field in bacterial foraging optimization," Soft Computing, vol. 18, no. 4, pp. 797-807, 2014.

[42] Y. Zhang, R. Liu, X. Wang, H. Chen, and C. Li, "Boosted binary Harris hawks optimizer and feature selection," Engineering with Computers, vol. 1, pp. 1-30, 2020.

[43] W. Li, Z. Chen, X. Gao, W. Liu, and J. Wang, "Multimodel framework for indoor localization under mobile edge computing environment," IEEE Internet of Things Journal, vol. 6, no. 3, pp. 4844-4853, 2018.

[44] L. Xiang, X. Shen, J. Qin, and W. Hao, "Discrete multi-graph hashing for large-scale visual search," Neural Processing Letters, vol. 49, no. 3, pp. 1055-1069, 2019.

[45] J. Zhang, W. Wang, C. Lu, J. Wang, and A. K. Sangaiah, "Lightweight deep network for traffic sign classification," Annals of Telecommunications, vol. 75, no. 7, pp. 369-379, 2020.

[46] S. R. Zhou, J. P. Yin, and J. M. Zhang, "Local binary pattern (LBP) and local phase quantization (LBQ) based on gabor filter for face representation," Neurocomputing, vol. 116, pp. 260-264, 2013.

[47] B. Xiong, K. Yang, J. Zhao, W. Li, and K. Li, "Performance evaluation of openflow-based software-defined networks based on queueing model," Computer Networks, vol. 102, pp. 172-185, 2016.
[48] J. Wang, Y. Yang, T. Wang, R. S. Sherratt, and J. Zhang, "Big data service architecture: a survey," Journal of Internet Technology, vol. 21, no. 2, pp. 393-405, 2020.

[49] S. He, K. Xie, K. Xie, C. Xu, and J. Wang, "Interference-aware multisource transmission in multiradio and multichannel wireless network," IEEE Systems Journal, vol. 13, no. 3, pp. 2507-2518, 2019.

[50] D. Zhang, T. Yin, G. Yang, M. Xia, L. Li, and X. Sun, "Detecting image seam carving with low scaling ratio using multi-scale spatial and spectral entropies," Journal of Visual Communication and Image Representation, vol. 48, pp. 281-291, 2017.

[51] M. Long, F. Peng, and H. Y. Li, "Separable reversible data hiding and encryption for HEVC video," Journal of RealTime Image Processing, vol. 14, no. 1, pp. 171-182, 2018.

[52] J. Zhang, S. Zhong, T. Wang, H. C. Chao, and J. Wang, "Blockchain-based systems and applications: a survey," Journal of Internet Technology, vol. 21, no. 1, pp. 1-14, 2020.

[53] Y. Zhang, "Towards augmented kernel extreme learning models for bankruptcy prediction: algorithmic behavior and comprehensive analysis," Neurocomputing, vol. 430, pp. 185-212, 2020.

[54] D. Zhao, "Chaotic random spare ant colony optimization for multi-threshold image segmentation of 2D Kapur entropy," Knowledge-Based Systems, vol. 216, Article ID 106510, 2020.

[55] J. Tu, "Evolutionary biogeography-based whale optimization methods with communication structure: towards measuring the balance," Knowledge-Based Systems, vol. 212, Article ID 106642, 2020.

[56] Q. Tang, K. Yang, D. Zhou, Y. Luo, and F. Yu, "A real-time dynamic pricing algorithm for smart grid with unstable energy providers and malicious users," IEEE Internet of Things Journal, vol. 3, no. 4, pp. 554-562, 2015.

[57] S. He, W. Zeng, K. Xie, H. Yang, M. Lai, and X. Su, "PPNC: privacy preserving scheme for random linear network coding in smart grid," KSII Transactions on Internet and Information Systems (TIIS), vol. 11, no. 3, pp. 1510-1532, 2017.

[58] M. Mortazavi, M. K. M. Nasution, F. Abdolahzadeh, M. Behroozi, and A. Davarpanah, "Sustainable learning environment by mobile-assisted language learning methods on the improvement of productive and receptive foreign language skills: a comparative study for asian universities," Sustainability, vol. 13, no. 11, p. 6328, 2021.

[59] M. Mortazavi, F. Tansu Hocanın, and A. Davarpanah, "Application of quantitative computer-based analysis for student's learning tendency on the efficient utilization of mobile phones during lecture hours," Sustainability, vol. 12, no. 20, p. 8345, 2020.

[60] A. Davarpanah, "Parametric study of polymer-nanoparticles-assisted injectivity performance for axisymmetric two-phase flow in EOR processes," Nanomaterials, vol. 10, no. 9, p. 1818, 2020.

[61] W. Shan, "Double adaptive weights for stabilization of moth flame optimizer: balance analysis, engineering cases, and medical diagnosis," Knowledge-Based Systems, vol. 214, Article ID 106728, 2020.

[62] C. Yu, "SGOA: annealing-behaved grasshopper optimizer for global tasks," Engineering with Computers, vol. 1, pp. 1-28, 2021.

[63] J. Hu, H. Chen, A. A. Heidari, and M. Wang, "Orthogonal learning covariance matrix for defects of grey wolf optimizer: insights, balance, diversity, and feature selection," Knowledge-Based Systems, vol. 213, Article ID 106684, 2021. 
[64] A. Davarpanah and B. Mirshekari, "A mathematical model to evaluate the polymer flooding performances," Energy Reports, vol. 5, pp. 1651-1657, 2019.

[65] A. Davarpanah, R. Shirmohammadi, B. Mirshekari, and A. Aslani, "Analysis of hydraulic fracturing techniques: hybrid fuzzy approaches," Arabian Journal of Geosciences, vol. 12, no. 13, pp. 1-8, 2019.

[66] X. Zhao, D. Li, B. Yang, C. Ma, Y. Zhu, and H. Chen, "Feature selection based on improved ant colony optimization for online detection of foreign fiber in cotton," Applied Soft Computing, vol. 24, pp. 585-596, 2014.

[67] H. Yu, W. Li, C. Chen, and J. Liang, "Dynamic gaussian barebones fruit fly optimizers with abandonment mechanism: method and analysis," Engineering with Computers, vol. 1, pp. 1-29, 2020.

[68] M. Ebnali, R. Fathi, R. Lamb, S. Pourfalatoun, and S. Motamedi, "Using augmented holographic UIs to communicate automation reliability in partially automated driving," in Proceedings of the AutomationXP@ CHI, Honolulu, HI, USA, 2020.

[69] M. Rezaei, F. Farahanipad, A. Dillhoff, R. Elmasri, and V. Athitsos, "Weakly-supervised hand part segmentation from depth images," in Proceedings of the 14th PErvasive Technologies Related to Assistive Environments Conference, pp. 218-225, Corfu, Greece, June 2021.

[70] Z. Chen, H. Li, Y. Bao, N. Li, and Y. Jin, "Identification of spatio-temporal distribution of vehicle loads on long-span bridges using computer vision technology," Structural Control and Health Monitoring, vol. 23, no. 3, pp. 517-534, 2016.

[71] P. Kiedrowski, "Driver's head tracking with pose estimation using computer vision technology under 2D environment," Advances in Computational Ences and Technology, vol. 11, no. 11, pp. 887-895, 2018.

[72] Z. Wang, H. Li, and X. Zhang, "Construction waste recycling robot for nails and screws: computer vision technology and neural network approach," Automation in Construction, vol. 97, pp. 220-228, 2019.

[73] B. Alizadeh Kharazi, A. H. Behzadan, and A. Behzadan, "Flood depth mapping in street photos with image processing and deep neural networks," Computers, Environment and Urban Systems, vol. 88, Article ID 101628, 2021.

[74] A. Kharazi Bahareh, D. Li, Z. Zang, and A. Behzadan, "Feasiblity study of urban flood mapping using traffic signs for route optimization," in Proceeding of the 28th EG-ICE International Workshop on Intelligent Computing in Engineering, pp. 572-581, Berlin, Germany, 2021.

[75] H. Tian, T. Wang, Y. Li et al., "Computer vision technology in agricultural automation-a review," Information Processing in Agriculture, vol. 7, no. 1, pp. 1-19, 2020.

[76] Q. Xi, Q. Zhang, W. Hu, and W. Xin, "Computer visionbased library management system," Science \& Technology Libraries, vol. 35, no. 2, pp. 172-182, 2016.

[77] Rosario and Uceda-Sosa, "Computer vision and image processing in intelligent systems and multimedia technologies," Computing Reviews, vol. 57, no. 9, p. 535, 2016.

[78] M. T. García-Ordás, E. Alegre, V. González-Castro et al., "A computer vision approach to analyze and classify tool wear level in milling processes using shape descriptors and machine learning techniques," International Journal of Advanced Manufacturing Technology, vol. 90, no. 5-8, pp. 1-15, 2016.

[79] Y. Liu, X. Wang, F. Du et al., "Computer vision detection of mold breakout in slab continuous casting using an optimized neural network," International Journal of Advanced Manufacturing Technology, vol. 88, no. 1-4, pp. 1-8, 2016.

[80] Y. Liu, X. Wang, F. Du et al., "Computer vision detection of mold breakout in slab continuous casting using an optimized neural network," International Journal of Advanced Manufacturing Technology, vol. 88, no. 1, pp. 557-564, 2017.

[81] B. Zhang, L. Zhou, and J. Zhang, "A methodology for obtaining spatiotemporal information of the vehicles on bridges based on computer vision," Computer-Aided Civil and Infrastructure Engineering, vol. 34, no. 6, pp. 471-487, 2019.

[82] A. Ray Sarkar, G. Sanyal, and S. Majumder, "Participatory design for selection of icons to represent daily activities of living for a vision-based rehabilitation-cum-assistance system for locked-in patients," Disability and Rehabilitation: Assistive Technology, vol. 15, no. 3, pp. 282-291, 2020.

[83] J. Wang, Y. Liu, D. Zhang, H. Peng, and Y. Zhu, "A new computer vision based multi-indentation inspection system for ceramics," Multimedia Tools and Applications, vol. 76, no. 2, pp. 2495-2513, 2017.

[84] J. Wang, Y. Liu, D. Zhang et al., "A new computer vision based multi-indentation inspection system for ceramics," Multimedia Tools and Applications, vol. 76, no. 2, pp. 1-19, 2016.

[85] A. Brunetti, D. Buongiorno, G. F. Trotta, and V. Bevilacqua, "Computer vision and deep learning techniques for pedestrian detection and tracking: a survey," Neurocomputing, vol. 300, pp. 17-33, 2018.

[86] T. Zhe, L. Huang, Q. Wu, J. Zhang, C. Pei, and L. Li, "Intervehicle distance estimation method based on monocular vision using 3D detection," IEEE Transactions on Vehicular Technology, vol. 69, no. 5, pp. 4907-4919, 2020.

[87] Mihai-Cosmin Iațeşen, "10 creativity and innovation in visual arts through form and space having symbolic value," Review of Artistic Education, vol. 14, no. 1, pp. 207-216, 2017.

[88] J. W. Amoroso, J. Marra, C. S. Dandeneau, and K. Brinkman, "Cold crucible induction melter test for crystalline ceramic waste form fabrication: a feasibility assessment," Journal of Nuclear Materials, vol. 486, pp. 283-297, 2017.

[89] J. Briales and J. Gonzalez-Jimenez, "A minimal closed-form solution for the perspective three orthogonal angles ( $\mathrm{P} 3 \mathrm{oA})$ problem: application to visual odometry," Journal of Mathematical Imaging and Vision, vol. 55, no. 3, pp. 266283, 2016.

[90] W. Long, L. Xia, and X. L. Wang, "A rapid automatic analyzer and its methodology for effective bentonite content based on image recognition technology," China Foundry, vol. 13, no. 5, pp. 322-326, 2016.

[91] W. Xing, S. Zhao, and S. Zhang, "Blind identification technology of computer generated image based on texture recognition," Journal of Computational and Theoretical Nanoscience, vol. 14, no. 7, pp. 3312-3322, 2017.

[92] S. Satoh, "Image and video technology," Facial Expression Recognition Using Cascaded Random Forest Based on Local Features, Springer, vol. 10799, pp. 42-53, Berlin, Germany, 2018.

[93] Y. Wang, S. Wang, Y. Liu et al., "Recognition of group activities based on M-DTCWT and elliptic mahalanobis metrics," in Communications in Computer and Information Science, vol. 757, pp. 113-122, Springer, Berlin, Germany, 2018.

[94] H. W. Huang, Q. T. Li, and D. M. Zhang, "Deep learning based image recognition for crack and leakage defects of 
metro shield tunnel," Tunnelling and Underground Space Technology, vol. 77, pp. 166-176, 2018.

[95] Z. Wang, M. Liu, M. Dong, and L. Wu, "Riemannian alternative matrix completion for image-based flame recognition," IEEE Transactions on Circuits and Systems for Video Technology, vol. 27, no. 11, pp. 2490-2503, 2017.

[96] S. H. Shirazi, A. I. Umar, S. Naz, and M. I. Razzak, "Efficient leukocyte segmentation and recognition in peripheral blood image," Technology \& Health Care Official Journal of the European Society for Engineering \& Medicine, vol. 24, no. 3, pp. 335-347, 2016.

[97] Q. Gao, J. Wang, X. Ma, X. Feng, and H. Wang, "CSI-based device-free wireless localization and activity recognition using radio image features," IEEE Transactions on Vehicular Technology, vol. 66, no. 11, pp. 10346-10356, 2017.

[98] M. Kumar and Priyanka, "Various image enhancement and matching techniques used for fingerprint recognition system," International Journal of Information Technology, vol. 11, no. 4, pp. 767-772, 2019.

[99] H. Ren, J. Zhang, M. Zhu, and M. Liu, "Particle-size analysis of wood fiber and powder based on image processing and recognition," Journal of Information Technology Research, vol. 11, no. 3, pp. 105-118, 2018.

[100] W. Tan, B. Yan, and C. Lin, "Beyond visual retargeting: a feature retargeting approach for visual recognition and its applications," IEEE Transactions on Circuits and Systems for Video Technology, vol. 28, no. 11, pp. 3154-3162, 2018.

[101] G. Javidannia, M. Bemanian, and M. Mahdavinejad, "Performance oriented design framework for early tall building form development; seismic architecture view," in Proceedings of the eCAADe38. Cumincad, Berlin, Germany, September 2020.

[102] G. Javidannia, M. Bemanian, M. Mahdavinejad, S. Nejat, and L. Javidannia, "Generative design workflow for seismic-efficient architectural design of tall buildings; A multi-object optimization approach," in Proceedings of the SimAUD, ACM Digital Library, 2021.

[103] M. Rezaei and N. Naderi, "Persian signature verification using fully convolutional networks," 2019, http://arxiv.org/ abs/1909.09720.

[104] M. F. Nezhadnaeini, M. Hajivand, M. Abasi, and S. Mohajeryami, "Optimal allocation of distributed generation units based on two different objectives by a novel version group search optimizer algorithm in unbalanced loads system," Revue Roumaine des Science Techniques, vol. 61, pp. 338-342, 2016.

[105] M. Abasi, J. Mahmood, A. Saffarian, and S. G. Seifossadat, "A novel complete dynamic and static model of 48-pulse VSCbased GUPFC for parallel transmission lines," International Journal of Industrial Electronics, Control and Optimization, vol. 3, no. 4, pp. 447-457, 2020.

[106] M. Abasi, J. Mahmood, A. Saffarian, and S. G. Seifossadat, "Accurate simulation and modeling of the control system and the power electronics of a 72-pulse VSC-based generalized unified power flow controller (GUPFC)," Electrical Engineering, vol. 102, no. 6, pp. 1795-1819, 2020.

[107] B. Mafakheri, P. Gonnella, A. Bazzi, B. M. Masini, M. Caggiano, and R. Verdone, "Optimizations for hardwarein-the-loop-based V2X validation platforms," in Proceedings of the 2021 IEEE 93rd Vehicular Technology Conference (VTC2021-Spring), pp. 1-7, IEEE, Helsinki, Finland, April 2021. 